\title{
Os princípios da psicologia soviética e os problemas do psicodiagnóstico da atividade cognitiva ${ }^{1}$
}

\author{
Los principios de la psicología Soviética y los problemas del \\ psicodiagnóstico de la actividad cognoscitiva
}

N.F. Talizina ${ }^{2}$

A abordagem para o diagnóstico da atividade cognitiva é decisivamente determinada pela teoria psicológica subjacente a ela.

O estudo clássico dos testes baseia-se nas seguintes premissas: 1) as capacidades do homem são genéticas e, por isso, são, de fato, invariáveis; 2) encontramos, com pouca frequência, um alto nível de desenvolvimento das capacidades. Em geral, considerando o nível de desenvolvimento das capacidades, as pessoas têm uma distribuição normal 3) o produto final das capacidades variáveis está sujeito a controle, mas, para solucionar tarefas de diagnóstico, não serão analisados o conteúdo dessas capacidades nem as particularidades de sua utilização.

Todos os procedimentos para elaboração e seleção de testes são derivados logicamente dessas premissas. A primeira premissa fez com que o estudo de testes estabelecesse uma contraposição entre desenvolvimento e ensino, entre capacidades e habilidades e ainda entre conhecimentos e hábitos. A segunda premissa centra sua atenção, durante a preparação e seleção dos testes, na curva de distribuição normal (curva Gaussiana). O teste que não fornece uma distribuição normal não é considerado válido. A terceira premissa constitui a base da abordagem quantitativa das capacidades do homem, explica a ausência de dados relacionados à análise qualitativa, tanto dos diferentes tipos de atividade cognitiva quanto do desenvolvimento intelectual do homem em geral. As posições iniciais indicadas também determinaram a função básica dos testes: a diferenciação das pessoas de

\footnotetext{
${ }^{1}$ Tradução do capitulo: Talízina, N. F. Los principios de la psicología Soviética y los problemas del psicodiagnóstico de la actividad cognoscitiva, En: Antología de la psicología pedagógica y de las edades. C. Habana. Editorial Pueblo y Educación. 1986. Inicialmente publicado na Coleção Probliemi programirovannovo obuchenia organizada por N. F. Talízina. Moscou, 1979.

${ }^{2}$ Nina Fiódorovna Talízina, Universidade Estadual de Moscou, Rússia.
} 
acordo com índices puramente quantitativos e o prognóstico com base em seu sucesso em atividades futuras. Sabe-se que as bases teóricas indicadas não suportaram a prova da época: o estudo das provas, em muitos países ocidentais, foi forçado a se retirar gradualmente dessas posições e buscar novos caminhos. Em particular, a contribuição da educação para o desenvolvimento das capacidades humanas é cada vez mais reconhecida, havendo uma transição para escalas qualitativas do desenvolvimento intelectual, usadas primeiramente nos trabalhos de J. Piaget.

Com base no postulado marxista sobre a natureza social da personalidade humana, a psicologia soviética considera as capacidades como o produto da formação obtida ao longo da vida. Um papel decisivo nesse processo corresponde ao ensino, que não se opõe ao desenvolvimento, mas conduz o precede, dirige e cria sua zona de desenvolvimento próximo. Por isso, uma mudança no tipo de aprendizado ocasiona uma mudança no curso do desenvolvimento. Essa abordagem do desenvolvimento das capacidades humanas dá à psicologia a possibilidade de estudá-las em seu processo de formação, não nas condições do curso espontâneo desse processo, mas nas condições de sua direção.

Os conhecimentos atuais sobre o sistema estrutural e funcional da atividade bem como os vínculos e as relações entre seus elementos permitem calcular, teoricamente, os tipos mais produtivos de atividade intelectual, em particular aqueles que garantem a solução de alguns tipos de tarefas teóricas.

A teoria da aprendizagem que aplica uma abordagem ativa ao processo de aprendizagem de P. Ya. Galperin permite formar tipos modelados de atividades com qualidades previamente definidas. Essa abordagem modifica substancialmente as possibilidades de ensino e permite, ao mesmo tempo, alcançar outros índices de desenvolvimento intelectual.

Por isso, o problema das normas evolutivas do desenvolvimento intelectual é apresentado de uma nova maneira: uma mudança no tipo de aprendizado gera uma mudança no curso do desenvolvimento e, consequentemente, uma mudança nas possibilidades evolutivas do homem.

A abordagem relativa à atividade que se aplica às capacidades humanas, ao intelecto humano, requer a revelação substancial das neoformações que movem o 
homem de um estágio de desenvolvimento intelectual para outro, bem como a indicação da peculiaridade qualitativa da atividade cognitiva em cada um desses estagios. Com essa abordagem, o diagnóstico pressupõe a existência de modelos de conteúdo daqueles tipos de atividades que se submetem à investigação. Isso se refere, em igual medida, tanto ao diagnóstico destinado a avaliar o nível de desenvolvimento intelectual em geral quanto ao diagnóstico relacionado à determinação do grau de formação dos diferentes tipos de atividade cognitiva.

Isso, por sua vez, significa que o diagnóstico deve seguir as investigações psicológicas nessa área, realizadas a partir das posições teóricas indicadas.

As possibilidades de direcionar o processo de aprendizagem e, ao mesmo tempo, o processo de desenvolvimento do homem fornecem a base para considerar que as realizações no desenvolvimento intelectual das pessoas não devem ser distribuídas em correspondência com a curva de Gaus. Essa curva reflete a distribuição de realizações quando o curso do processo de capacitação é espontâneo.

A abordagem exposta sobre a compreensão do conteúdo e a natureza do intelecto bem como sobre as capacidades que o compõem leva a uma outra forma de solução dos problemas do psicodiagnóstico.

Primeiro, o problema da norma evolutiva depende das condições históricosociais e, principalmente, do tipo de ensino e educação (ELKONIN, 1966). Segundo a norma evolutiva deve ser representada como uma característica do conteúdo da atividade cognitiva do homem: o desenvolvimento intelectual ocorre como uma substituição ou mudança dos estados qualitativamente peculiares da atividade cognitiva. $\mathrm{O}$ diagnóstico deve ter como objetivo estabelecer a existência dos tipos normativos de atividade e seus estados (VENGUER, 1974).

A valoração do estado de uma atividade específica deve ser realizada de acordo com uma escala que reflete os estágios fundamentais da gênese de qualquer tipo de atividade intelectual, enquanto a valoração do desenvolvimento intelectual deve ser realizada de acordo com uma escala que reflete a lógica das neoformações. Nessa última valoração, deve ser atribuída importância decisiva, não ao que constitui a zona de desenvolvimento atual, mas ao que está na zona de desenvolvimento próximo. 
Com essa abordagem, a função do psicodiagnóstico varia substancialmente, perdendo seu objetivo discriminatório, embora retendo dentro de certos limites, o papel prognóstico. Sua principal função deve ser a de determinar as condições que mais favorecem o desenvolvimento futuro da pessoa em questão e auxiliar na elaboração de programas de ensino e de desenvolvimento que levem em consideração a peculiaridade do estado real de sua atividade cognitiva.

Essa abordagem anula o contraste de capacidades, por um lado, e de conhecimentos, habilidades e hábitos, por outro. O conhecimento sempre constitui um elemento de alguma atividade, enquanto habilidades, hábitos e capacidades sempre constituem uma atividade (ação ou sistema de ações) caracterizada por uma série de particularidades.

Com a abordagem usada, o procedimento para preparar os testes, em princípio, também varia. $\mathrm{O}$ sistema básico de tarefas é calculado para a execução da atividade diagnosticada, levando em consideração seus estados fundamentais. Os subtestes são feitos em correspondência com a estrutura da atividade em questão e têm como objetivo determinar a existência e o estado das várias ações que entram nessa atividade. A validade do teste é dada na medida em que haja correspondência com a atividade a que o diagnóstico se destina.

O problema do psicodiagnóstico do nível de desenvolvimento intelectual está relacionado a uma série de problemas complementares com os quais não vamos lidar agora. O diagnóstico do nível de formação dos diferentes tipos de atividade cognitiva pode ser realizado com sucesso quando é utilizada a teoria da formação por etapas das ações intelectuais (GALPERIN, 1959, 1965; TALÍZINA, 1975).

A partir das posições da abordagem por nós adotada, realizamos um ciclo de pesquisas (1975-1979) dedicado ao diagnóstico do nível de formação dos procedimentos elementares do pensamento lógico.

Examinemos os resultados de algumas dessas investigações. Antes de tudo, analisemos a pesquisa que realizamos em conjunto com A. I. Dimitrova (1976).

$\mathrm{O}$ trabalho foi realizado com crianças de cinco a nove anos de idade e teve como objetivo diagnosticar o nível de desenvolvimento de cada uma delas quanto ao procedimento de classificação. A escolha desse procedimento foi feita 
porque já havia sido estudada em uma série de investigações por J. Piaget e B. Inhelder (1963) e Lingart (1970) entre outros.

Com base na abordagem que desenvolvemos em termos de diagnóstico, a primeira tarefa foi determinar o sistema de ações que constituem esse procedimento.

O modelo desenvolvido por N. A. Podgorietskaia (1974) foi tomado como base. O sistema objetivo das ações incluídas por ela no procedimento de classificação passou no teste experimental na investigação de L. F. Ermakovaia (1974). Nesta investigação, o modelo foi definitivamente desenvolvido e representado pelo seguinte sistema de ações: 1) ação para determinar o fundamento da classificação; 2) ação de divisão de todos os objetos da classe em suas subclasses componentes; 3) ação que garanta a manutenção do mesmo fundamento para a divisão da classe em subclasses em um único nível; 4) ação para incluir a subclasse na classe; 5) ação para o uso dos quantificadores: todos, alguns, um, nenhum; 6) ação para determinar a ordem lógica dos fundamentos durante a classificação; 7) ação de desenvolvimento consecutivo das subclasses de acordo com dois e mais fundamentos da classificação.

Além disso, consideramos um sistema de ações relacionadas à determinação das características dos objetos: gerais, distintivas, substanciais. Essas ações antecipam a formação do procedimento de classificação e são preliminares em relação a ele.

Uma análise especial mostrou que as tarefas de diagnóstico utilizadas nos trabalhos de J. Piaget e B. Inhelder assim como nos trabalhos de Y. Lingart são, por um lado, excessivas e, por outro, insuficientes, pois não abrangem uma série de ações que entram no procedimento de classificação. Portanto, as tarefas utilizadas por eles não permitem estabelecer o estado das diferentes ações ou procedimentos em geral, de acordo com todo o sistema de características fundamentais da atividade: forma, generalização, medida de redução e medida de assimilação (automação, rapidez, entre outras).

De maneira geral, o procedimento diagnóstico desenvolvido teve a seguinte forma: primeiro, as tarefas foram colocadas de acordo com a forma da linguagem externa, começando pelas tarefas de alto grau de complexidade e terminando pelas mais simples. No caso de os alunos apresentarem dificuldades, as tarefas 
foram propostas na mesma ordem, de maneira perceptiva (as tarefas que eram realizadas por meio da linguagem externa não foram realizadas de maneira perceptiva). Os problemas que não foram resolvidos de maneira perceptiva foram colocados na mesma ordem de complexidade na forma materializada, e os não resolvidos dessa maneira foram apresentados na forma material.

Além disso, as tarefas variavam de acordo com o material utilizado: primeiro, em relação aos problemas, o procedimento indicado foi aplicado em um material artificial e, depois, em um material natural. As demais características da atividade não foram diagnosticadas.

A pesquisa realizada revelou que a abordagem diagnóstica relacionada à atividade permite estabelecer o nível de desenvolvimento de cada componente que entra no procedimento de classificação. Assim, verificamos que, das ações preliminares, a mais formada é a ação de distinguir características nos objetos; das ações básicas, a mais formada é a ação de incluir a subclasse na classe. Por outro lado, a ação de distinguir características substanciais no objeto e a ação de usar quantificadores de igualdade estavam em um baixo nível de assimilação.

A transição de formas de ação geneticamente tardias para formas mais atuais, do ponto de vista genético, levou a um maior sucesso das ações dos investigados. Detectamos que a forma material é accessível para todos os nossos pesquisados. A maioria das ações é realizada pelas crianças de maneira perceptiva e materializada. Percebemos ainda que, para uma parte dessas crianças, também é accessível a forma da linguagem externa da ação.

Esses dados diferem substancialmente dos obtidos por Y. Lingart: a metodologia desenvolvida por ele permite julgar apenas a forma perceptiva da atividade, a qual constitui a base da classificação aditiva. Por isso, sua metodologia não permite determinar o estado das diferentes ações que entram nessa atividade, assim como tampouco as crianças que já têm acesso à forma da linguagem externa, nem as que não atingiram a forma perceptiva.

Ressalta-se que, se a metodologia Y. Lingart fosse aplicada, as crianças que realizam essa atividade com sucesso na forma materializada e material estariam entre aqueles que não saberiam classificar. 
Em crianças, a determinação do estado qualitativo de cada ação que entra no procedimento da classificação permite fornecer recomendações fundamentadas e de conteúdo sobre o programa de seu desenvolvimento posterior.

Os resultados citados demonstram o potencial dessa abordagem diagnóstica da atividade cognitiva. É importante observar aqui que a determinação da atividade encontrada após qualquer tarefa de teste assim como a avaliação desta com base nos critérios qualitativos de P. Ya. Galperin permitem valorar essas tarefas com unidade de critérios, de acordo com a validade, e estabelecer, com precisão, suas possibilidades de solução.

A abordagem psicodiagnóstica da atividade cognitiva, a partir das posições adotadas, apresenta uma série de novos problemas que não haviam surgido anteriormente nessa área. Um desses problemas é o da estratégia de pesquisa da atividade cognitiva que evita o efeito instrucional. Levantamos esse problema junto com V. M. Deriabin para ser investigado de uma maneira especial.

A investigação demonstrou que o diagnóstico de cada tipo de atividade deve ser determinado pela ação central e depois produzido em ordem inversa à formação (DERIABIN, 1979).

Conhecer o conteúdo dos tipos de atividades diagnosticadas também possibilita distinguir as ações centrais e gerais que entram na constituição de alguns tipos de atividades. Isso permite diagnosticar essas ações a partir de uma única atividade e evitar o diagnóstico repetido durante a investigação de outros tipos de atividade.

\section{Tradução e revisão:}

Sandra Cristina Bezerra de Barros ${ }^{3}$

Betânia Leite Ramalho ${ }^{4}$

\footnotetext{
${ }^{3}$ Professora Adjunta do Departamento de Letras da Universidade do Rio Grande do Norte UFRN. ORCID: https://orcid.org/0000-0002-2803-8663.

${ }^{4}$ Professora titular do Centro de Educação - UFRN. ORCID: https://orcid.org/0000-0003-01392416. E-mail: betania.ramarlho@gmail.com.
} 